\title{
What Influences Customer Satisfaction When? Product and Service Over Time
}

\author{
Shueh-Chin Ting \\ Professor, Program of Educational Entrepreneurship and Management \\ Department of Education, National University of Tainan, Taiwan \\ E-mail: tingsc@ms49.hinet.net
}

Received: May 31, 2016

Accepted: June 15, 2016

Published: July 1, 2016

doi:10.5296/jmr.v8i3.9538

URL: http://dx.doi.org/10.5296/jmr.v8i3.9538

\begin{abstract}
Though researchers have examined the changes in the effects of product and service performance on customer satisfaction, the short time frames of most studies prevents deeper understanding of this relationship. This study collects information from pre-purchase to 15 years post-purchase from 11,056 potential and existing automobile customers in the Taiwan market. The data is analyzed by a regression model. Results reveal that the importance of both product and service performance change over long time and the long-term trends of product and service performance weights are non-linear. In addition, from pre-purchase to the second year post-purchase, service weight is higher than product weight, but after the third year, product weight exceeds service weight. Product and service weight on customer satisfaction over time exhibit curvilinear relationships. Therefore, which one of product or service a company should stress depends on the stage in the customer relationship.
\end{abstract}

Keywords: Customer satisfaction, Dynamic, Non-linear, Over time, Weight 


\section{Introduction}

For a successful company, customer satisfaction is an important goal. When a product or service is unable to meet customer expectations, there is an immediate effect on customer satisfaction. Although many unsatisfied customers do not complain, at the next purchase, they may switch to competitors (Shen, Tan, and Xie, 2000).

Customer satisfaction is determined by product performance and service performance. In the automobile industry, the automobiles themselves and dealer service are two important sub-systems in the automobile consumption system. In the past in Taiwan, many companies were only concerned with product. However, as the economy developed, they increasingly depended on service to enhance customer perceived value. If companies can effectively manage the two subsystems of product and service, they can appropriately allocate their resources (Mittal, Kumar, and Tsiros, 1999).

Khalifa and Shen (2009) argued that in the literature satisfaction is seen as a static evaluation state. Such a static view overlooks the possibility that customers may change their evaluations with experience. Thus, it does not account for the dynamic nature of satisfaction. Their results demonstrate the necessity of a temporal conceptualisation of customer satisfaction. In addition, while most researchers have used regression analysis to determine the weights of the effect of product and service on customer satisfaction, study data are often derived from a single cross section, without considering the effect of the passage of time on customer satisfaction (Anderson and Mittal, 2000). Thus, whether the determined weights can be generalized to each stage of the customer relationship has not been investigated. Customers at different stages of contact with the company may have different perceived values for product and service (Mittal and Katrichis, 2000). The factors driving customer satisfaction may shift over time (Mittal et al., 1999). Therefore, the effect of product and service on customer satisfaction is not fixed, and companies must consider the influence of time (Mittal, Katrichis, and Kumar, 2001).

Few studies have explored the dynamics of product and service weight (Homburg, Koschate, and Hoyer, 2006; Mittal and Katrichis, 2000; Mittal et al., 1999), Further, such dynamics related research generally only explores short intervals, such as two years post-purchase. Since long-term studies of this issue do not exist, no study provides complete weight variations over the entire customer relationship.

In addition, previous studies of customer satisfaction dynamics often only focused on two time points. As such, the change of product and service weight between the two time points often is presented as if it was a linear relationship, neglecting potential weight variation during the time interval.

Previous studies of customer satisfaction focused on post-purchase issues. This study supposes that pre-purchase conditions are not the same as post-purchase conditions for customers since the level of customer contact and understanding of the product, as well as customer demands, are different. Thus, pre-purchase and post-purchase, customer concerns may differ. 
Due to the lack of long-term studies discussed before, in this study a long interval (fifteen years) with multiple time points is used to examine the evolution of the relationship between product and service weight and customer satisfaction. Clarification of this relationship will provide managers with a useful reference for determining marketing strategies to enhance customer satisfaction under different stages in the customer relationship.

\section{Dynamic View of Attribute Importance}

In recent years, several studies have adopted a dynamic view in analyzing product and service effects. Anderson and Mittal (2000) indicated that, while companies use attribute performance to enhance customer satisfaction, they should consider that attributes have different levels of importance to customers in different market segments. For example, new customers are concerned with different attributes than old customers. After old customers become familiar with a product or service, attribute importance will change. Similarly, Mittal and Katrichis (2000) found that the attributes by which a company obtains new customers are frequently very different from those by which a company retains loyal customers. Therefore, a company should develop different strategies to obtain new customers and to retain loyal customers.

Anderson and Mittal (2000) contended that when companies use attribute performance to promote overall customer satisfaction, they should care about the customer's entire consumption experience. Therefore, an automobile company not only should investigate the customer satisfaction immediately after selling an automobile to the customer, but also should do so over a long period of time. Furthermore, a customer satisfaction survey should include the core product and service, because customer satisfaction is influenced not only by the core product but also by the service.

In studies of customer value and satisfaction, researchers have proposed that customer perceptions of service attributes will change over time (Nilsson-Witell and Fundin, 2005). Woodruff (1997) argued that important attributes perceived by customers will change with time, and when a product is in purchase, in use, and after use, the customers' perceived value for each attribute of a product will change. Parasuraman (1997) similarly contended that customers' perceived value of an attribute is a dynamic concept which changes over time. Oliver (2010) suggested that when a customer purchases a product and then uses it, the considered attributes are different. Ha (2012) also found that the relationship between attribute-level evaluation and satisfaction is dynamic and changes over time. For three of the five attributes examined, there was a shift in weights from time point $\mathrm{T}$ and time point $\mathrm{T}+1$.

Mittal et al. (1999) empirically investigated customers' perceptions of new automobiles. The results showed that for a customer at just-purchase, the service attributes are more important than the product attributes. However, with the passage of time, the importance of the product attributes increases. Exploring the auto industry, Mittal and Katrichis (2000) found that new customers focus on service and that attention shifts to the automobile itself over time.

If a company can understand that the importance of an attribute to customers varies over the time of their relationship with the company, it will be helpful in implementing customer 
strategy, retention strategy, resource management, staff training, and customer relationship management (Mittal and Katrichis, 2000).

\section{Theoretical Foundation}

\subsection{Customer demand}

Even from a static perspective, a company should not use the same strategy for all customers, as customer demands differ. From the dynamic perspective, if a company stresses the long-term customer relationship, and focuses attention on each customer's long-term consumption cycle, the company should understand the shifts in customer demand and adjust its strategy accordingly (Mittal and Katrichis, 2000).

Mittal, Katrichis, Forkin, and Konkel (1994) argue that the attributes for the maximization of customer satisfaction are related to customer goals. Mittal et al. (2001) observe that the weights of attributes determining overall customer satisfaction will change over time and that such weight changes are related to changes in the customer's consumption goals. This assertion is consistent with means-end concept of overall customer satisfaction. The attributes by which a company measures customer satisfaction should be revised as customer demands change (Woodruff, 1997). New customer and loyal customer demands are quite different (Mittal and Katrichis, 2000). Given this, not all attributes are equally related to customer satisfaction. Instead, only attributes that affect customer goals can affect customer satisfaction. These customer goals will change over time. Thus, customers will demand different attributes over time, a fact that should be reflected in company customer strategies.

In the pre-purchase stage of an automobile, the customer lacks understanding in many areas, such as product-related knowledge and company service options. Hence, the customer desires that service personnel have the ability and willingness to help them. Thus, in the pre-purchase stage, the interaction between service personnel and the customer is very important. In the post-purchase stage of an automobile, the customers accumulate experience of the automobile's actual operation and the company's service. As time passes, customers become familiar with the product and service processes. Thus, customers have less need for service personnel provide information. Instead, they want an automobile with good quality. In this stage, the determinant of customer satisfaction is the automobile, rather than the service.

\subsection{Attribute performance variability}

Attribute performance variability refers to the stable degree of attribute performance. Its variability will affect the perceptually salient degree: attributes with more unstable performance will be more noticed by customers, causing such attribute to become more important to them. Furthermore, attribute performance variability may be related to time. Hence, attribute weights that affect customer satisfaction could change over time (Mittal et al., 2001). For a purchased durable product, the customer can observe whether its attribute performance is stable over the long-term. If customers find that an attribute's performance is unstable, they may focus on the attribute (customer sensitivity to the attribute will increase), increasing its importance. For example, if the gas mileage performances of different automobile models exhibit a very large difference, then fuel consumption may have a greater 
impact on customer satisfaction for such cars (Mittal et al., 1999).

\section{Hypothesis Development}

We divide automobile buyers' contact with their automobile company into two major periods of time, pre-purchase and post-purchase. Pre-purchase is divided into the two stages of information collection and purchase decision. We use customer demand and attribute performance variability as the theoretical foundation to explain the importance of the service and the product to customer satisfaction over time.

First, this study explains the information collection period in the pre-purchase. Because automobiles are a high price product, buyers usually have relatively low purchase frequency and low brand experience. In addition, automobile buyers have higher perceived risk. Buyers thus strive to collect information before the purchase in order to understand the product. To look for information, they may ask direct contact with the automobile, access the company website, call service personnel, and discuss face-to-face with the dealer's sales staff. Buyers in the information collection period thus require many different kinds of services. We argue that in the information collection period, the primary determinant of customer satisfaction is service. Hence, we hypothesize:

H1: During the pre-purchase information collection period, service has a higher weight than product in determining automobile buyers' customer satisfaction.

After the information collection period, the buyers enter the purchase decision period. First, we compare the service weights and the product weights in the purchase decision period. This study argues that the buyer's main demand in the purchase decision period remains the service, because the buyer's knowledge of the automobile is largely derived from services provided by the company. However, the services that buyers need in the purchase decision period are not the same as in the information collection period. In the purchase decision period, buyers need the seller's explanation of more detailed questions of the automobile purchase such as signing the contract, handling the insurance, transferring ownership, and handing over the automobile.

This may also be viewed from the standpoint of attribute variability. In the purchase decision period, the automobile has not yet been used and its performance is thus fixed. Service, by contrast, has greater variability than the automobile's performance in the purchaser's perception. Therefore, service has the higher salience. In sum, in the purchase decision period, the buyer has higher demand for service and the service has higher variability. Therefore this study posits that the importance of service is higher than product in the purchase decision period.

The service weights for customer satisfaction also change from the information collection period to the purchase decision period. In the information collection period, generally speaking, what the buyer wants to understand is the basic product knowledge. Conveying this knowledge to the buyers is easier for service personnel because they can use standardized operational norms. In the purchase decision period, the buyer wants to understand more detailed matters, which may be more individualized or specific, and which are more difficult 
to standardize. Thus, service performance variability in the purchase decision period is greater, causing service salience to be higher, increasing service importance.

Conversely, the buyer's understanding of the automobile undergoes no great change between the purchase decision period and the information collection period, meaning that the buyer's perception of the automobile attribute's performance remains stable. Since this causes the automobile (product) salience to be lower, the automobile's importance effect on customer satisfaction is less than that of service.

H2: In the purchase decision period, the service has a higher weight than the product in determining the automobile buyer's customer satisfaction. In addition, comparison with the information collection period, during the purchase decision period, the service weight increases, and the product weight falls.

This study defines the just-purchased stage as the period up to three years after purchase of the automobile. The biggest difference between the post-purchase stage and pre-purchase stage is that buyers can experience the automobile's performance during the post-purchase stage. Satisfaction is likely to change as new experience-based drivers emerge (Bhattacherjee and Premkumar, 2004), especially during the first year, because the automobile's use has a huge change. It seems reasonably obvious that the effect of the automobile on customer satisfaction will increase in the first year after the purchase. In the second and the third year after the purchase, the buyer's experience of the automobile's use is richer than before, giving the buyer better ability to judge automobile quality. This should cause the automobile's weight in buyer satisfaction to increase. If automobile quality is stable (in general, a new automobile does not have problems within the first three years), the automobile's salience will decline, reducing its importance weight. Thus, the above two effects counteract each other. Thus, automobile's weight during the second and third year, compared to its weight in the first year, does not exhibit a significant change.

The first year is also crucial for service. The buyer does not understand the just-purchased automobile and often needs help from the service personnel. Therefore the service within the post-purchase stage of one year remains quite important. However, after one year post-purchase, the situation changes. The buyer, with the accumulation of experience, becomes familiar with the automobile's operation and basic product knowledge. Contacts with service personnel fall. Moreover, with the accumulated service experience, the buyer becomes accustomed to the service patterns the company provides, and service's salience declines. Therefore, after a year post-purchase, the effect of service on customer satisfaction should rapidly decline.

H3: In the post-purchase stage of one year, the influence weight of the product on the automobile buyer's customer satisfaction increases. The first three years after purchase, the influence weight of the product on the automobile buyer's customer satisfaction remains stable. In the post-purchase stage of one year, the service is as important as the pre-purchase stage, and after one year post-purchase, the importance of service rapidly declines. 
After three years post-purchase, the patterns of service importance and automobile importance change and are expected to increase, with the automobile's importance exceeding that of service. The reason service importance increases in this period is that after three years of use problems with the automobile begin appearing, causing customer demand for automobile repair to increase. Thus, three years post-purchase, this new service demand increasingly affects customer satisfaction.

By the same token, in the first three years after the purchase, the automobile's condition is stable, and the customer returns to the dealership only for maintenance. The customer thus pays less attention to the product, and the effect of the automobile itself on customer satisfaction is relatively low during this period. However, over time the automobile and its parts wears out, and repairs become more frequent, increasing customer expenses and time costs. Thus, three years post-purchase, the influence weight of the automobile on customer satisfaction begins to increase.

After three years post-purchase, though the importance of both the service and the automobile on customer satisfaction increase, we contend that the automobile's importance is higher than that of service, and the importance disparity between them grows as time passes. The older the automobile, the more car trouble is experienced, causing customers to focus on the automobile's quality. After three years, the buyer's basic need is a vehicle that works and the most important goal of service is to help the customer maintain the automobile in good condition. If the company provides good service, but does not provide good automobile quality, the customer will not accept this result. However, if the automobile quality is good, but the service is bad, the customer will accept this because good automobile quality leads to lower service demand and because the buyer's priority is a working car. Therefore, beginning in the fourth year, the automobile becomes more important than the service.

Given that after three years, the product performance variability of the automobile starts to increase, its attribute importance in customer satisfaction grows. Service, however, remains relatively more stable than the product. Service can be controlled by the standardized operational norms of the company, and the customer is familiar with the service from experience. Because the variability of service performance is lower than the variability of automobile performance, the effect of service on customer satisfaction is also lower. In sum, the automobile's importance in customer satisfaction is greater than that of service.

H4: After three years post-purchase, the influence weights of the product and the service on the automobile buyer's customer satisfaction begin to increase. However, the product weight increase is greater than that of the service weight. Moreover, the effect of the product on the automobile buyer's customer satisfaction is greater than the service.

\section{Study Design}

\subsection{Study sample}

This study covers a long period of time, from the buyer's information collection period before the purchase to fifteen years after the purchase. Therefore, a product with a long usage life is necessary. The automobile meets this requirement. 


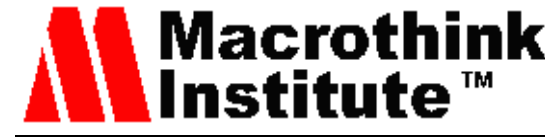

To facilitate sample collection, we contacted automobile company headquarters in Taiwan and asked for their cooperation, promising in exchange to provide them with our findings on customer perceptions of automobile quality, service quality, and customer satisfaction in the Taiwan market, and then help them create improvement strategies. Firms that chose to cooperate provided us with the basic information on their customers in Taiwan. We then interviewed these customers by telephone to collect the study data. Pre-purchase participant materials came primarily from records of visitors in automobile's show rooms sampled over a six month period. The automobile company provided this study with the visitors' names, visiting dates, and their telephone numbers. Post-purchase participant materials came primarily from the customer materials in the repair shop of the automobile company, which provided us with the automobile owners' names, auto purchase dates, and their telephone numbers. During the telephone interviews, the study again confirmed the stage of the participants's contact with the company.

This study obtained a total of 12,032 customers' basic information and successfully interviewed 11,056 customers by telephone. The demographic structure of the 11,056 effective participants is described as follows. The participants consisted of 6,570 males $(59.42 \%)$ and 4,486 females (40.58\%), 4,980 (45.04\%) were from northern Taiwan, 3,065 $(27.72 \%)$ were from central Taiwan, and 3,011 (27.23\%) were from southern Taiwan. In age, 2,309 were less than 30 years old $(20.88 \%), 2,542$ were from 30 to 39 years old $(22.99 \%)$, 2,571 were from 40 to $49(23.25 \%), 2,192$ were from 50 to $59(19.83 \%)$, and 1,442 were over $60(13.04 \%)$.

\subsection{Operational definition}

\subsubsection{Customer satisfaction}

Customer satisfaction refers to the customer's overall psychological feeling toward the company.

\subsubsection{Automobile performance}

Automobile performance refers to the customer's overall evaluation of the automobile's quality.

\subsubsection{Service performance}

Service performance refers to the customer's overall evaluation of the service quality.

\subsubsection{Time}

Time refers to the stages, in which the customer interacts with the company. The time is divided into 17 stages, including two pre-purchase stages, information collection and purchase decision, and 15 post-purchase stages corresponding to the first through 15 th year after the purchase.

\subsection{Variable measurements}

At the beginning of a telephone interview, interviewers confirmed each customer's stage (information collection period, purchase decision period, or which year after the purchase) as the time variable. For customers who had not purchased, we asked "Why did you come to $\mathrm{x}$ 
company's show room in x year, x month, and x date?" For the customers who had purchased, we asked "Is this automobile purchased in x year, x month, and x date?" After above the question, then we asked the following three questions to measure automobile performance, service performance, and overall customer satisfaction on a ten point semantic scale.

1. At that time/Now (pre-purchase/post-purchase), how did/do you feel about their automobiles? (very bad/very good)

2. At that time/Now (pre-purchase/post-purchase), how did/do you feel about their services? (very bad/very good)

3. Overall, at that time/now (pre-purchase/post-purchase), what was/is the level of your satisfaction? (very dissatisfied/very satisfied)

\subsection{Analysis method}

To test the hypotheses, this study estimates the following regression model.

Model (1): CS $=b_{0}+b_{1} \times P R+b_{2} \times S E+b_{3} \times P R \times$ time $+b_{4} \times S E \times$ time $+r$

CS denotes customer satisfaction, PR denotes product performance (i.e., automobile), SE denotes service performance, time denotes the generic term of all dummy variables (in total, 16 dummy variables because of 17 time periods), and $\mathrm{r}$ denotes random error.

\section{Study Results}

According to the result of the regression model (1), this study acquires the product weights and service weights at each of the 17 time periods which are arranged in Table 1. In addition, the results are also given in chart form in Figure 1 to more clearly depict the changing trends of the weights of both product and service on customer satisfaction throughout the customer relationship.

H1 posits "In the information collection period of the pre-purchase stage, the service has a higher weight than the product in determining the automobile buyer's customer satisfaction." In the information collection period, i.e. time is at stage -1, the weight of the influence of the product on customer satisfaction for the automobiles' buyer is 0.23 , and service is 0.47 . Thus, service has a greater weight than the product. Hence, H1 is supported.

H2 states "In the purchase decision period, the service has a higher weight than the product in determining the automobile buyer's customer satisfaction. In addition, compared to the information collection period, the service weight increases, and the product weight falls." In the purchase decision period time is at 0 , the weight of influence of the product on customer satisfaction for the automobiles' purchasers is 0.15 , and the service is 0.58 . Thus, service has a greater weight than product. The product weight falls from 0.23 to 0.15 , while the service weight increases from 0.47 to 0.58 . Hence, $\mathrm{H} 2$ is supported.

H3 states "In the post-purchase stage of one year, the influence weight of the product on the automobile buyer's customer satisfaction increases. The first three years after purchase, the influence weight of the product on the automobile buyer's customer satisfaction remains 
stable. After one year post-purchase, the importance of service rapidly declines." Comparing the post-purchase stage of the first year (time is at 1) with the purchase decision period (time is at 0 ), the influence weight of the product on the automobile buyer's customer satisfaction increases from 0.15 to 0.28 . However, the product weights for the the first three years post-purchase (first year $=0.28$, second $=0.27$, and third $=0.29$ ) are stable. The service weight at the post-purchase stage of the first year (0.57) maintains the same high level as the purchase decision period (0.58). Following this, the service weight declines to 0.37 in the second year and 0.17 in the third year. Thus, H3 is supported.

Table 1. Product and service weight over time.

\begin{tabular}{ccc}
\hline time & product weight & service weight \\
\hline-1 & 0.23 & 0.47 \\
0 & 0.15 & 0.58 \\
1 & 0.28 & 0.57 \\
2 & 0.27 & 0.37 \\
3 & 0.29 & 0.17 \\
4 & 0.34 & 0.19 \\
5 & 0.40 & 0.21 \\
6 & 0.47 & 0.26 \\
7 & 0.55 & 0.31 \\
8 & 0.64 & 0.32 \\
9 & 0.71 & 0.32 \\
10 & 0.77 & 0.32 \\
11 & 0.81 & 0.32 \\
12 & 0.83 & 0.32 \\
13 & 0.84 & 0.32 \\
14 & 0.85 & 0.32 \\
15 & 0.85 & 0.32 \\
\hline
\end{tabular}

Notes:

Time definitions: -1 denotes the information collection period; 0 denotes the purchase decision period; 1-15 denotes which year after the purchase of the automobile (e.g., 1 is one full year after the purchase date; 2 is the second full year after the purchase date.)

H4 states "After three years post-purchase, the influence weights of the product and the service on the automobile buyer's customer satisfaction begin to increase. However, the product weight increase is greater than that of the service weight. Moreover, the effect of the product on the automobile buyer's customer satisfaction is greater than the service." As time passes, the weight of the automobile continuously increases: $0.29,0.34,0.40,0.47,0.55,0.64$, 0.71 , and 0.77 in the third through the tenth years, respectively. Beginning from the 11 th year, the automobile weight stabilizes. During the same period (after the post-purchase stage of three years), although the influence weight of service on customer satisfaction also increases, the increase is smaller $(0.32-0.17=0.15)$ than that of the product $(0.85-0.29=0.56)$. Significant increases in the service weight occur in the fifth year $(0.21)$ to the sixth year $(0.26)$, and again 


\section{Macrothink}

from the sixth year $(0.26)$ to the seventh year $(0.31)$. In addition, from the third year to the 15 th year after purchase, at any given point in time, the product weight is greater than the service weight. Thus, H4 is supported.

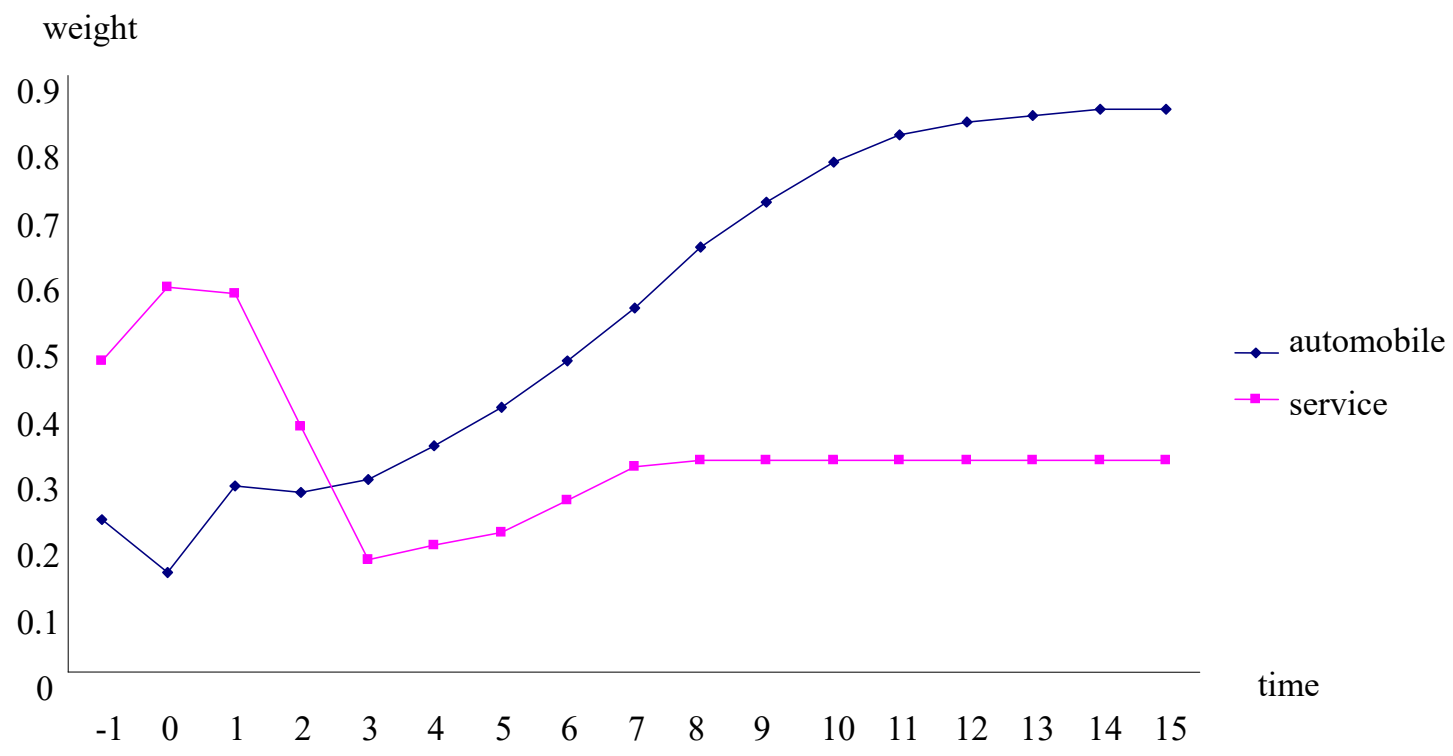

Figure 1. Influence weight of automobile and service on customer satisfaction over time

\section{Discussion}

This study uses automobile buyers as participants to explore the influence of the products and services provided by automobile companies on customer satisfaction over long time. There are four key features of this study. First, this study simultaneously integrates product and service in order to compare the influences of both the product and the service on customer satisfaction. Second, this is a dynamic study, which increases the consideration of the time factor, in order to understand whether the effects of the product and the service on customer satisfaction are related to time. Third, most previous studies were limited to a comparison of product and service weight under two time points (Mittal and Katrichis, 2000; Mittal et al., 1994; Mittal et al., 2001). However, this study examines 17 time points to observe the trends in the weight changes. Fourth, in the selection of the research time points, this study includes both the pre- and post-purchase stages. Therefore, this study explores the customer relationship more thoroughly than any previous similar study. These features of this study allow the effect of both product and service on customer satisfaction to be examined in greater detail, expanding academic understanding of the topic.

\section{Conclusion}

This study shows the changing effect of product and service on customer satisfaction over time. We find that the shape of the effect of product and service weight on customer 
satisfaction over time is a curvilinear. During the post-purchase stages, the change in weights over time is also non-linear. Previous studies examine the weights at two time points or over a short time period but do not provide detailed changes in the weight across the entire time period. This study solves this problem and clearly indicates the changing situation of the respective effects of the weights of both product and service on customer satisfaction in the long-term. The effect of the weight of service on customer satisfaction increases from the information collection period to the purchase decision period, and then reaches its highest point during the purchase decision period and the first year post-purchase. It then declines rapidly in the second and the third year, rises slowly from the fourth to the seventh year, and then at the beginning of the eighth year becomes stable to the fifteenth year, the final year of collected data. The effect of the the product on customer satisfaction is somewhat low and declines from the information collection period to the purchase decision period in which the weight reaches its lowest point. At the post-purchase stage of the first year, the product weight climbs, and in the first three years, the product weights remain close, but from the beginning of the fourth year the product weight begins to rise. After the tenth year, it flattens and stabilizes.

Figure 1 shows two curves depicting the weight changes. Both product and service weight change curves eventually reach a plateau, meaning that the weights do not continuously rise without limit. Moreover, the service curve flattens earlier than the product curve. This is likely because automobile owners become used to company services after a few years. Thus, the service weight quickly becomes stable. However, automobiles increasingly suffer from problems after several years. This causes the customer to focus on the automobile's quality, which in turn causes the automobile's weight to rise. Thus, while service remains the same, the quality of the car declines over time, leading the curve of rising automobile weight to flatten later. Therefore, even after the service weight has entered its flat period, the automobile weight is still rising. When the automobile reaches its 11 th year, the automobile user has become accustomed to the automobile's need for repair, and the automobile weight stabilizes.

Looking at product and service weights by time point, in the information collection period, the purchase decision period, first year post-purchase, and second year post-purchase, the service is more important than the automobile. Starting from the third year, the relative importance reverses and the automobile becomes more important than the service and this difference grows with time. Starting from the third year, service appears to play only an auxiliary role, helping users smoothly use the automobile. In other words, the user needs the automobile more than the service from the beginning of the third year. In addition, as the automobile becomes older, more problematic and more unstable, based on the principle of the attribute performance variability, the automobile becomes more important. Therefore, the weight of the automobile is higher than the weight of service after the third year post-purchase, and the difference grows over time.

\section{Limits and Recommendations}

To clearly understand whether the effects of product and service on customer satisfaction 
change over the long-term, this study extends its sampling period from the pre-purchase information collection period to fifteen years post-purchase. It is difficult for a researcher to conduct a longitudinal study for a panel of respondents whose responses are tracked beyond 15 years. Therefore, this study uses a cross-section of this long period consisting of different participants for the different contact stages. To reduce the bias from the sample characteristics of each respondent group, this study collects a large sample for each contact stage. However, since this is not a longitudinal study, the application of our results needs care.

The key point of this study lies in the comparison of product and service. To avoid blurring the focus, we do not explore their attributes. Therefore, we cannot ensure that all product and service attributes have the same results as this study. We believe that further exploration of product and service at the attribute level is necessary. For example, the automobile's interior space and the automobile's transmission system are both product attributes but they behave differently. The interior space is more or less fixed over time, but the transmission performance declines and parts must be periodically renewed. Therefore, from the perspective of attribute performance variability, the weight of the automobile's inner space on customer satisfaction may decline over time, but the weight of the automobile's transmission system on customer satisfaction may increase over time.

This study finds that service weight changes in a curvilinear fashion. However, this study does not define whether the service types needed by customers are the same in earlier and later periods. That question requires further study.

Our research product is the automobile, which falls into the utilitarian product category. Homburg et al. (2006) also studied a utilitarian product, CD-ROM tutorials, finding that the effect of affective factors on customer satisfaction declined over time while the effect of cognitive factors increased. Though there are differences between this study's product and service and Homburg et al.'s (2006) cognition and affection, we argue that product has a close relationship with cognition, whereas service has a close relationship with affection. If this thinking is correct, in terms of utilitarian products, this study's findings are consistent with those of Homburg et al. (2006). However, Homburg et al. (2006) argued that the importance of cognitive factors on utilitarian products is higher than on hedonic products. Therefore, whether the findings of this study based on a utilitarian product are applicable to those of hedonic products requires further exploration.

\section{Managerial Implications}

This study finds that product and service have different weights for customers at different stages of the customer relationship. This means that a company should not use the same strategy to manage customer satisfaction throughout the lifetime of the customer relationship, but strategies should be based on the varying effects of product weight and service weight in different relationship stages. This study argues that the weight changes have two causes: first, customers at different stages have different demands, and second, customers perceive different variability for the attribute performance in different stages. If an attribute has a high weight at one stage, it means at that stage, customers will have a high demand for the 
attribute and/or the attribute has great performance variability. This study suggests that the companies wanting to promote customer satisfaction should pay attention to whether product or service has the higher weight at each stage in the customer relationship in order to cater to customer demands and maintain product or service quality.

This study's findings will be helpful in company personnel training, especially for service personnel who are in direct contact with the customers. For potential customers before purchase and new customers who have just purchased, the company has to provide especially good service, as these two stages are the highest weight stages of service. From the third to the fifth year after purchase, service has low weight, implying that the company should only maintain basic interaction with customers at this stage. As the automobile grows older, the service weight again starts to increase. We suggest that the company strengthen service for customers during the mid and late contact period, especially repair services.

We also find that before purchase, the product weight fluctuates, then becomes stable in the initial period after purchase. From the beginning of the third year, the product weight is continuously rising over time until in the 15th year it reaches its highest weight. Obviously, during the mid and late contact period, the product is increasingly important, its importance eclipsing that of service. Thus, the automobile's quality is the core of customer satisfaction for customers of older automobiles. This study suggests that the automobile company should request the manufacturing unit and the research and development unit to provide automobile parts of high quality to older customers with older automobiles, and request the technical unit to assist older automobiles' customers in maintaining their vehicles in good condition. These strategies for product performance improvement may promote customer satisfaction among owners of older vehicles.

\section{Acknowledgement}

The author is grateful to National Science Council in Taiwan for the financial support (NSC 96-2416-H-024-001)

\section{References}

Anderson, E. W., \& Mittal, V. (2000). Strengthening the satisfaction-profit chain. Journal of Service Research, 3(2), 107-120. http://dx.doi.org/10.1177/109467050032001

Bhattacherjee, A., \& Premkumar, G. (2004). Understanding changes in belief and attitude toward information technology usage: A theoretical model and longitudinal test. MIS Quarterly, 28(2), 229-254.

Ha, H. Y. (2012). The effects of online shopping attributes on satisfaction-purchase intention link: A longitudinal study. International Journal of Consumer Studies, 36(3), 327-334. http://dx.doi.org/10.1111/j.1470-6431.2011.01035.x

Homburg, C., Koschate, N., \& Hoyer, W. (2006). The role of cognition and affect in the formation of customer satisfaction: A dynamic perspective. Journal of Marketing, 70(3), 21-31. http://dx.doi.org/10.1509/jmkg.70.3.21 


\section{Macrothink}

Journal of Management Research

ISSN 1941-899X

2016, Vol. 8, No. 3

Khalifa, M., \& Shen, K. N. (2009). Modelling electronic customer relationship management success: Functional and temporal considerations. Behaviour \& Information Technology, 28(4), 373-387. http://dx.doi.org/10.1080/01449290802030373

Mittal, V., \& Katrichis, J. M. (2000). Distinctions between new and loyal customers. Marketing Research, 12(1), 26-32.

Mittal, V., Katrichis, J. M., Forkin, F., \& Konkel, M. (1994). Does satisfaction with multi-attribute products vary over time? A performance based approach. Advances in Consumer Research, 21(1), 412-417.

Mittal, V., Katrichis, J. M., \& Kumar, P. (2001). Attribute performance and customer satisfaction over time: Evidence from two field studies. Journal of Services Marketing, 15(5), 343-356. http://dx.doi.org/10.1108/EUM0000000005655

Mittal, V., Kumar, P., \& Tsiros, M. (1999). Attribute-level performance, satisfaction, and behavioral intentions over time: A consumption-system approach. Journal of Marketing, 63(2), 88-101. http://dx.doi.org/10.2307/1251947

Nilsson-Witell, L., \& Fundin, A. (2005). Dynamics of service attributes: A test of Kano's theory of attractive quality. International Journal of Service Industry Management, 16(2), 152-168. http://dx.doi.org/10.1108/09564230510592289

Oliver, R. L. (2010). Satisfaction: A behavioral perspective on the consumer $\left(2^{\text {nd }}\right.$ ed.), New York, NY.: Irwin/McGraw-Hill Companies. http://dx.doi.org/10.4324/9781315700892

Parasuraman, A. (1997). Reflections on gaining competitive advantage through customer value. Journal of the Academy of Marketing Science, 25(2), 154-161. http://dx.doi.org/10.1007/BF02894351

Shen, X. X., Tan, K. C., \& Xie, M. (2000). An integrated approach to innovative product development using Kano's model and QFD. European Journal of Innovation Management, 3(2), 91-99. http://dx.doi.org/10.1108/14601060010298435

Woodruff, R. B. (1997). Customer value: The next source for competitive advantage. Journal of the Academy of Marketing Science, 25(2), 139-153. http://dx.doi.org/10.1007/BF02894350 